Miomir Korać

Arheološki institut Beograd

Srđan Marković

Multimediaworx

Jelena Obradović

Multimediaworx

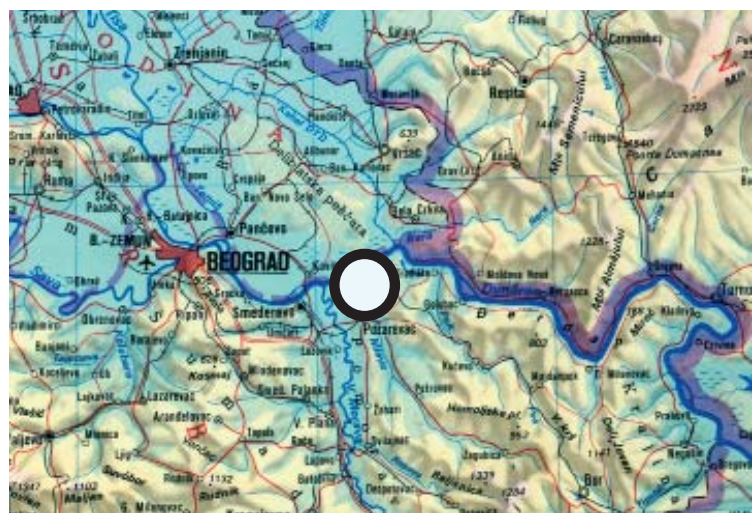

Viminacium, Stari Kostolac, Srbija

LAT 44 44'09" / LONG 21 12 ' 42"

\title{
PRIMENA VR PANORAMA U VIZUELIZACIJI KULTURNOG NASLEĐA NA INTERAKTIVNOM CD ROM-U "VIMINACIUM LUMEN MEUM"
}

\begin{abstract}
ABSTRAKT
Virtuelna simulacija prostora i objekata u vizuelizaciji kulturnog nasleđa ima nemerljiv značaj za tačnost i autentičnost prostornih informacija, jer obezbeđuje efekat "biti tamo" - pogled na prostor odnosno objekat iz svih uglova.

Značajna karakteristika fotografisanih VR panorama je u njihovoj realističnosti $i 3 D$ iluziji bez dodatih artificijelnih $3 D$ informacija, dok modelovane $i$ renderovane panorame omogućavaju najpribližniju rekonstrukciju ili nadogradnju realnog ambijenta.

KLJUČNE REČI: VIRTUELNA REALNOST, VR PANORAME, SIMULACIJA, REALISTIČNOST, INTERAKTIVNOST, Quick Time
\end{abstract}

Pojava panorama po Oliveru Grau datira još iz antike, sa freskama koje su pokrivale zidove Vile Misterije u Pompeji. Slike koje su prikazivale figure koje učestvuju u Dionizijskim ritualima dozvoljavale su posetiocima vizuru od 360 stepeni, anticipirajući na taj način diorame i ciklorame koje su postale popularne u 19 . veku. Pronalazak perspektive u renesansi omogućio je umetnicima da još ubedljivije kreiraju iluziju trodimenzionalnih prostora.

Baldasare Perudijeva Salla delle Prospettive u Rimu iz 16. veka transformisala je čeoni zid sobe u portiku sa kolonadom koja gleda na iluzionističku perspektivu starog Rima.
Ideju oslikavanja kompletno cirkularnog platna u pravilnoj perspektivi patentirao je Robert Barker 1787. godine i konstruisao ga nekoliko godina kasnije. Grau takođe primećuje da je pojavu panorama karakterisala kombinacija medijske i vojne istorije. Rane panorame su služile u svrhu snimanja terena i izviđanja, ali njihov vojni uspeh je bio kratkog veka i uskoro ga je zamenila korist od propagande. Panoramske slike bitaka kao Anton fon Vernerova "Pobeda pruske nad francuskom vojskom 1870." postale su vrlo posećene atrakcije, iako su izvedene u vreme kada je proizvodnja panorama bila više industrijski nego umetnički proces. 
Sredinom 19. veka, spajanjem serije fotografija načinjenih iz jedne žarišne tačke u cilindričnu celinu nastaju diorame - panoramske obrtne slike.

Industrijski modus izrade iluzionističkih ili imersivnih iskustava nastavio se pronalaskom filma, koji je postao trenutni uspeh i velika atrakcija, i koji će u kasnijem dobu značajno uticati na napredak panorama razvojem 3D Cinema i Cinerame.

Iako će neki od ovih izuma kasnije biti prevaziđeni, nastojanje da se stvore potpuno imersivna okruženja nastavljeno je pojavom digitalne simulacije i interaktivnosti.

Umetnost i mediji su evoluirali od sredine 80tih kada su kompjuteri postali dovoljno snažni i široko dostupni da omoguće umetnicima da sarađuju sa tehničarima na vrlo kompleksnim interaktivnim projektima, često uz pomoć fondova iz istraživačkih laboratorija ili elektronskih umetničkih centara.

Značajan impaktu ekspanzijivirtuelnerealnosti načinio je Internet sa svojim nepreglednim mogućnostima za povezivanje ljudi i prostora, nudeći gotova i prefabrikovana rešenja za njihovo kreiranje, čime korisnici sami biraju stepen svog učešća u njima. Takva interaktivnost kontrolisana od strane korisnika dovela je i do ranih formi "teleprisustva" u vidu telekonferencija, ili multiplayer on line igara, preko mogućnosti daljinskog upravljanja kamerama ili mašinama, pa do razvoja novih oblika vizuelne umetnosti.

Za razliku od nekadašnjih panorama koje su predstavljale fizički svet, ali nisu dopuštale nikakvu interakciju ili navigaciju, kompjuterski generisana virtuelna okruženja su to omogućila, ali su ispočetka bila ograničena na ono što može biti predstavljeno 3D kompjuterskim modelima. Takvi ambijenti su zbog očiglednih nedostataka tehnologije najčešće predstavljali imaginarne ili fantazijske svetove, $i$ tek su se u poslednje vreme značajno približili realizmu.

Razvojem tehnologije snimanja fotografija preciznom opremom i njihovim povezivanjem $u$ kompjuterskom programu, stvorila se mogućnost da se virtuelno predstavi potpuno sferično fotografisano okruženje od 360 stepeni i na taj način omogući neposredni pristup realnom ambijentu.

Pošto vizuelizacija danas služi kao ključna komponenta naučne metode, kao takva mora biti adekvatno dokumentovana zajedno sa svim ostalim delovima naučnog istraživanja.

Oblast virtuelnog nasleđa je već dugo skoncentrisana na generisanje digitalnih rekonstrukcija istorijskih ili arheoloških artefakta ili lokacija koje bi sa dovoljnom uverljivošću predstavljale tačne reprezentacije svojih ekvivalenata iz stvarnog sveta.

Naglašena je važnost unapređenja percepcije realizma koja može biti postignuta i fotorealističnim i ne-fotorealističnim pristupima vizuelizaciji u sprezi sa interaktivnošcu.

$\mathrm{Na}$ primeru interaktivnog CD ROM-a "Viminacium lumen meum" pokazaćemo oba načina upotrebe virtuelnog okruženja u svrhu postizanja verne dokumentarističke vizuelizacije.

Kompjuterska grafika je od svoje pojave bila koncentrisana na kreiranje slika koje se ne mogu razlikovati od realnosti, što je od velike važnosti za brojne aplikacije gde je vizuelna tačnost ključna, kao što su oblasti medicinske obuke, dijagnostičke slike i hirurške simulacije, arhitektura, arheologija, inženjerstvo, industrija, audiovizuelne produkcije, simulacije letova i druge. U virtuelnoj reprezentaciji kulturnog nasleđa, arheoloških lokaliteta, arhitektonskim virtuelnim šetnjama i slično, fotorealizam se generalno smatra najvažnijom merom uspešne prezentacije.

Međutim kako je oblast virtuelne realnosti sazrevala i kretala u eksperiment i istraživanja, taj stav je ustuknuo pred shvatanjem da, u mnogim slučajevima, ono što interesuje posmatrača jeste postizanje uverljivih i verovatnih okruženja bez obzira da li se slika oslanja na realni svet ili ne.

Kombinacijomumetničkihitehnoloških metoda moguće je postići naučno validnu simulaciju koja bi stvorila iluziju realnosti, bilo unapređenjem 
karakteristika postojećeg stanja ambijenta (postprodukcijskim zahvatima, izoštravanjem, prosvetljivanjem, retuširanjem...), bilo putem precizne rekonstrukcije nekadašnjeg stanja.

Simuliranje posmatranja stvarnog okruženja i kretanja kroz njega, uz dodatnu mogućnost zumiranja na slike i objekte u maksimalnom kvalitetu, svojom sveobuhvatnošcu postaje neprocenljiv dokumentarni materijal, koji je s obzirom na svoju digitalnu prirodu moguće dalje koristiti kako u prezentacione i obrazovne tako i u naučne svrhe.

U oblasti kao što je arheologija virtuelna realnost značajno doprinosi pregledu i sumiranju iskopavanja kao i samom procesu istraživanja. Lokalitet je na taj način istraživačima vizuelno dostupan bez obzira na vremenske prilike ili druga ograničenja, a takođe predstavlja snažno informativno, obrazovno i u krajnjoj liniji promotivno sredstvo.

$\mathrm{Na}$ lokalitetu rimskog grada Viminacijuma, snimljeno je više panorama postojećeg stanja: terme, porta praetoria, memorije. Vođeno je računa da budu urađene u visokoj rezoluciji, čime je postignut njihov maksimalan kvalitet i mogućnost da budu posmatrane na punom ekranu.

Time je omogućeno isticanje detalja, čime se dodatno unapređuje proučavanje.

Fotorealistična panorama prvenstveno zahteva precizno snimanje lokaliteta fotoaparatom širokog objektiva. Dodatna oprema omogućava okretanje fotoaparata oko svoje žarišne tačke za tačan broj stepeni, da bi se uzelo onoliko slika koliko je potrebno kompjuterskom programu da ih savršeno i bešavno "zalepi" jednu za drugu, i tako stvori iluziju jednog neprekidnog snimka.

Razvojem tehnologije, "cilindrične" panorame (koje prikazuju scenu od 360 stepeni bez pogleda na zenit i nadir) su danas prevaziđene, i zamenjene kubičnim (360 X 180 stepeni) panoramama koje omogućavaju pun doživljaj virtuelne realnosti bez ograničenja.

Reprezentacija pejzaža, objekata ili prizora iz prošlosti, poznata kao virtuelna arheologija, u stalnoj je potrazi za što vernijom simulacijom stvarnosti, i kako alati i tehnike napreduju, razni slikovni medijumi koji transformišu percepciju i impresiju realnosti napreduju takođe.

Kada je rec o baštini i arheologiji često se ističu dve bitne teme:

Prva, pitanje validnosti informacije, obično pominjano kao "autentičnost", i druga, doprinos tačnosti u reprezentaciji ovih informacija.

Arheolozi, istoričari i muzejski radnici pridaju veliki značaj autentičnosti i tačnosti, dok su na drugoj strani tehničari i umetnici koji se bave virtuelnom reprezentacijom nasleđa prirodno manje zainteresovani za tačnost samog sadržaja, a više za verodostojnu vizuelizaciju sadržaja.

U tom smislu, fotorealizam donekle miri ova dva stava, jer primenjen u virtuelnoj situaciji kada se korisnik smešta u autentičan prostor, on obezbeđuje kreaciju simulacije visokog kvaliteta koja je, koliko je to najviše moguće, približna realnosti.

Međutim, iako stavljanje akcenta na postizanje visokog stepena realizma rizikuje da se VR rekonstrukcija limitira na stvaranje istorijski tačnih, ali statičnih svetova koji ostavljaju malo mesta fleksibilnosti za interpretaciju, imersivne panorame su se pokazale kao napredna kombinacija preciznih i detaljnih informacija i interaktivnosti, čime je postignuto šire viđenje i funkcionalnije korišćenje podataka.

$\mathrm{Na}$ primeru panorama termi može se uočiti prava priroda fotorealističnog iskustva pogleda od 360 stepeni, kojim se obuhvata ceo natkriveni lokalitet. Na taj način očiglednije se sagledava prava veličina ambijenta, raspored i orijentacija elemenata u njemu, tekstura terena, stepen erozije, detalji na nalazištu, pa i izuzetnost konstrukcije kojim je natkriveno. Okretanjem u svim pravcima stvorena je iluzija prisustva u prostoru i na taj način dobijen neposredniji, sveobuhvatniji pristup slici na kojoj su odnosi između elemenata verno povezani i međusobno se dopunjuju.

Visoka rezolucija dozvoljava da se zumiranjem na pojedine delove panorama dobiju još detaljnije 


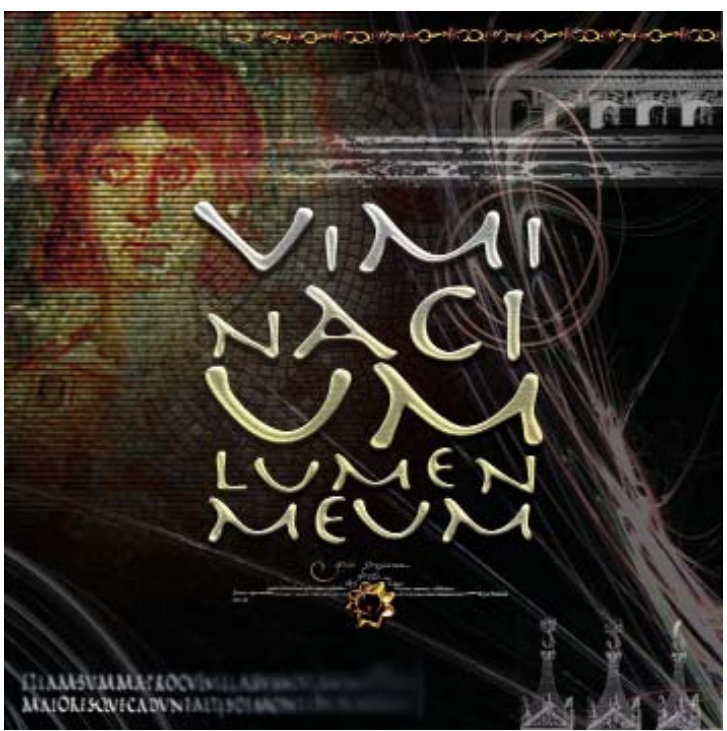

informacije $\mathrm{i}$ da se istaknu značajni aspekti lokacije.

Kada je reč o ne-fotorealističnoj reprezentaciji kulturne baštine, tradicionalni načini su kao moduse za prikazivanje istraživačkih analiza i pretpostavki, uglavnom obuhvatali ilustrovanje i maketarstvo. Čak i onda kada je kompjuterska grafika dostupna, arheolozi radije pribegavaju uvreženim metodama, najčešće zbog veće preciznosti, ili usredsređivanja na detalj. Ponekad je razlog i želja za očiglednom konfrontacijom posmatrača sa hipotezom, dok bi verna grafička predstava pretpostavljala istorijsku istinu, što se ponekad ne želi.

Međutim u situaciji kada istraživači tesno sarađuju sa umetnicima u procesu vizuelizacije, uspostavljajući veću kontrolu nad obradom podataka i njihovim uobličavanjem $u$ autentičnu reprezentaciju, primetan je pomak u rekonstrukciji lokaliteta i artefakta, pre svega pažljivim odabirom materijala, mapa, osvetljenja, poštovanjem nacrta, planova, preseka i pre svega nastojanjem da se kreira verodostojni utisak.

Zanimljiv primer za to je rekonstrukcija grobnica na lokalitetu rimskog grada Viminacijuma.

Freske od izuzetnog arheološkog, istorijskog i likovnog značaja pronađene u grobnicama, prenete su u požarevački Muzej radi restauracije. Sve dok restauracija ne bude gotova i freske ne budu vraćene na svoje mesto, pravi izgled grobnica neće biti dostupan ni posmatračima ni istraživačima.

Zato je kompjuterskom simulacijom virtuelne grobnice, postignut njen veran panoramski izgled, tako što je gabarit grobnice izmodelovan, a freske mapirane na zidove. Ovakav pogled na jedan važan istorijski spomenik je od izuzetnog značaja za dokumentovanje realnog stanja lokacije, a njegov doprinos je i u tome što ga čini dostupnim i preglednim i to iz vrlo zanimljive vizure - centra grobnice, odnosno jedne žarišne tačke, čime se dobija veoma širok pogled uz izvestan osećaj bestelesnosti. S obzirom da su grobnice zaista male po dimenzijama, ovako sveobuhvatan pogled ne bi bio moguć u realnosti.

Dodatna mogućnost interakcije posmatrača sa sadržajem panorame ne doprinosi samo boljem "osećaju" pri posmatranju ambijenta, već i merodavnijem procenjivanju informacija putem odabira relevantnosti onoga što se posmatra. Za razliku od filma gde je neko drugi režirao sadržaj, i dopustio nam da ga vidimo u redosledu i količini koju je sam odredio, uz vremensku limitaciju i lični ugao, panorame nam dozvoljavaju da se pozabavimo onim što nas interesuje sa željenom distancom i u željenom vremenu.

Kako istraživanje na lokalitetu Viminacijum bude napredovalo, planirano je da se i CD prezentacija razvija i nadograđuje, i u tom smislu još više unapredi interaktivnost. Poseban akcenat biće stavljen na mogućnost kreiranja virtuelnih šetnji kojima bi se povezali nodovi, odnosno tačke posmatranja, a time bi se dobila još jedna dimenzija kretanja kroz celo nalazište. Uz to, kako se podaci budu umnožavali ukazaće se potreba za njihovim boljim sortiranjem i jasnijom preglednošću, što se može postići QuickTime plug in-om koji obezbeđuje još detaljnije zumiranje na sam objekat do najsitnijih detalja, kao i kreiranjem VR objekata, tako da posmatrač uz pomoć miša može da okreće predmet sa svih strana i posmatra ga iz svih projekcija.

$\mathrm{Na}$ CD ROM-u "Viminacium lumen meum" koristili smo Quick Time Virtual reality (QTVR) 
plug in za prikazivanje virtuelnih panorama, koji je razvio Apple Computers. Njegova velika prednost $\mathrm{u}$ odnosu na druge plug in-ove koji se koriste za prikazivanje panorama je pre svega u njegovoj odličnoj (realističnoj) deformaciji, operativnosti sa visokim rezolucijama i u njegovoj multifunkcionalnosti, jer QuickTime kao "multimedijalni kontejner" može da sažme u jedan paket mnoštvo raznorodnog materijala.

Postoje dve klase QTVR slika: panoramski VR i VR objekata.

Panoramska slika se pravi tako što kamera rotirajući za precizan broj stepeni, snima seriju fotografija koje se kasnije spajaju u kompletnu (ili nekompletnu) panoramu. Slika VR objekta se pravi slično, s tim što je u tom slučaju kamera statična a objekat se okreće ispred nje.

Rezultat je slika na kompjuterskom ekranu oko koje možemo da se okrećemo.

U našem projektu smo se za sada zadržali isključivo na panoramskom VR-u.

Za izradu panorama pre svega je potreban fotoaparat (digitalni ili analogni, pri čemu je analogne fotografije kasnije neophodno vrlo precizno skenirati), široki objektiv (firma iPix je patentirala snimanje panorama pomoću ribljeg oka, pri čemu su samo dva snimka dovoljna da bi se napravila kubična panorama; ovo ima i svojih nedostatakau jasnoći snimka, alije veoma povoljna varijanta za brzo snimanje; inače generalno se preporučuju vrlo široki objektivi - $15 \mathrm{~mm}$ ili 18 $\mathrm{mm}$ fokalne dužine, ali se dobri rezultati mogu postići i sa $28 \mathrm{~mm}$ uz uzimanje više snimaka), rotaciona glava na koju se navija fotoaparat $i$ koja obezbeđuje precizno okretanje kamere pod odabranim uglom i za odabran broj stepeni (na tržištu postoji široka lepeza različitih rotacionih glava, među kojima se ističu Kaidan, Manfrotto i Agnus proizvođači), i konačno, stabilno postolje za kameru koje je moguće nivelisati.

Najrazličitiji softver je danas dostupan, a najviše se koristi: RealViz Stitcher, VR Worx, Helmut Dersch's PanoTools, QuickTime VR Authoring Studio, PhotoVista...

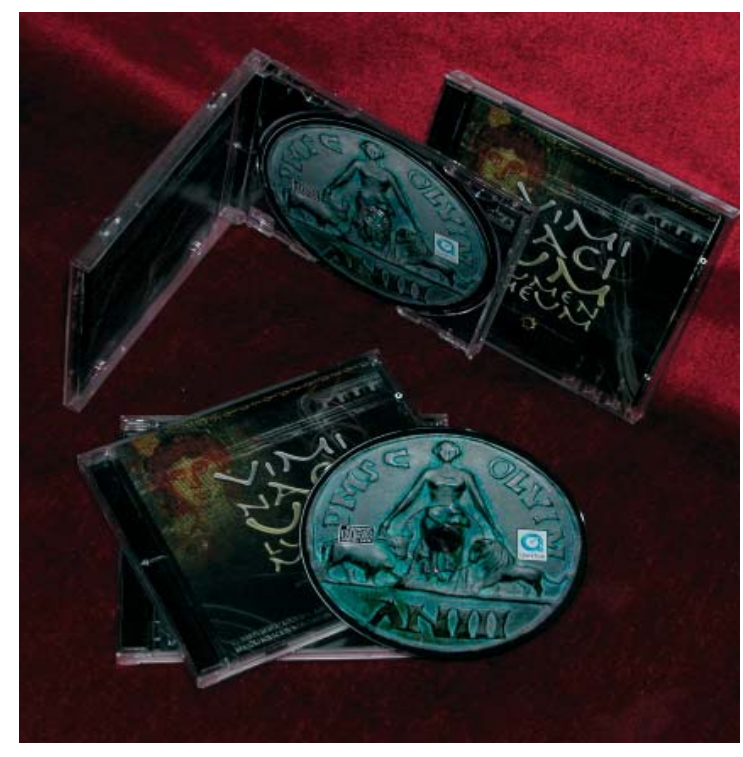

Da bi se prezentovao virtuelni materijal, neophodna je upotreba plug in-a. U zavisnosti od željenog kvaliteta i namene koriste se : Quick Time VR, Java, VRML, Shockwave, Flash...

U našem projektu koristili smo:

RealViz Stitcher 4.0

Nikon D100 fotoaparat

Objektiv DX 18-70 mm

Kaidan Quick Pan Spherical 4 rotator

Quick leveler (za preciznu nivelaciju rotatora)

Manfrotto tripod

Pri snimanju je bitno odrediti pravi broj fotografija u odnosu na širinu objektiva, jer je važno da se značajno preklapaju. Preporučuje se preklapanje slika izmedu 20 i $40 \%$. Na primer, objektivom od $15 \mathrm{~mm}$ dovoljno je uzeti 14 slika, dok je objektivom od $35 \mathrm{~mm}$ potrebno je uzeti 50 slika. Našim objektivom od $18 \mathrm{~mm}$ snimili smo 24 slike. Preklapanje je važno da bi program pronašao dovoljno zajedničkih tačaka na slikama, i na taj način ih lakše iskombinovao.

Najvažnija stvar prilikom snimanja panorama je nalaženje žarišne tačke (tzv. Nodal point).

To je tačka u kojoj se presecaju zraci koji ulaze kroz objektiv. Jedino rotacijom oko te tačke postiže se željena preciznost i izbegava pojava paralakse koju je nemoguće ispraviti u postprodukciji. Za profesionalni kvalitet je neophodna upotreba specijalizovanih panoramskih rotatora koji se 
nameštaju na postolje tripoda i koji služe da se fotoaparat precizno dovede u položaj potreban za slikanje i rotaciju po obe rose.

Sve slike slikane širokim objektivom su u manjoj ili većoj meri deformisane (tzv. "Barrel distortion"). Da bi spajanje bilo kvalitetno i bez vidljivih spojeva ta deformacija se mora ispraviti. $U$ tu svrhu se koriste mnogi programi (Helmut Derschovi Pano tools itd.) ili, u našem slučaju, Stitcher-ov ugradeni plugin za ispravljanje deformacija.

Nalaženje tačaka je automatsko i u slučaju Stitcher-a veoma uspešno. Algoritam koji koristi je vrlo efikasan tako da je potreba za ručnim spajanjem (tzv. "Force stitch") svedena na minimum. Još jedna od prednosti Stitchera u odnosu na ostale programe jeste korišćenje 3D interface-a u procesu spajanja slika. To nam omogućava da slike koje treba spajati u panoramu pomeramo po nevidljivoj sferi oko nas pre nego što ih dovedemo u željeni položaj.

Slike pre spajanja moraju da budu ujednačene u osvetljenju. Tu postoje dva problema: osvetljenost cele slike i pojava zatamnjenja na krajevima zbog upotrebe širokih objektiva (tzv. "Vignetting"). Rešenje u oba slučaja je korišćenje programa za grafičku obradu slike.

Upotreba blica je isključena zbog toga što se svetlosni zraci iz blica, zavisno od prostora $i$ objekata koji se nalaze oko nas, različito prostiru u prostoru i time manje ili više osvetljavaju kadar. Tako dobijena serija slika ima velike varijacije u osvetljenju. To ne utiče na spajanje slika u panoramu ali će zato dobijena panorama imati prepoznatljive oblasti različite osvetljenosti i samim tim će otkriti postojanje spojeva.

U okviru panorama postoji mogućnost pravljenja hot spotova, odnosno kreiranja oblasti na panorami koja služe kao dugmad ili okidači za pokretanje neke akcije, na primer za učitavanje nove panorame (na taj način se kreira virtuelna šetnja) ili slike uveličanog predmeta.

Razvojem novih tehnologija Virtuelna

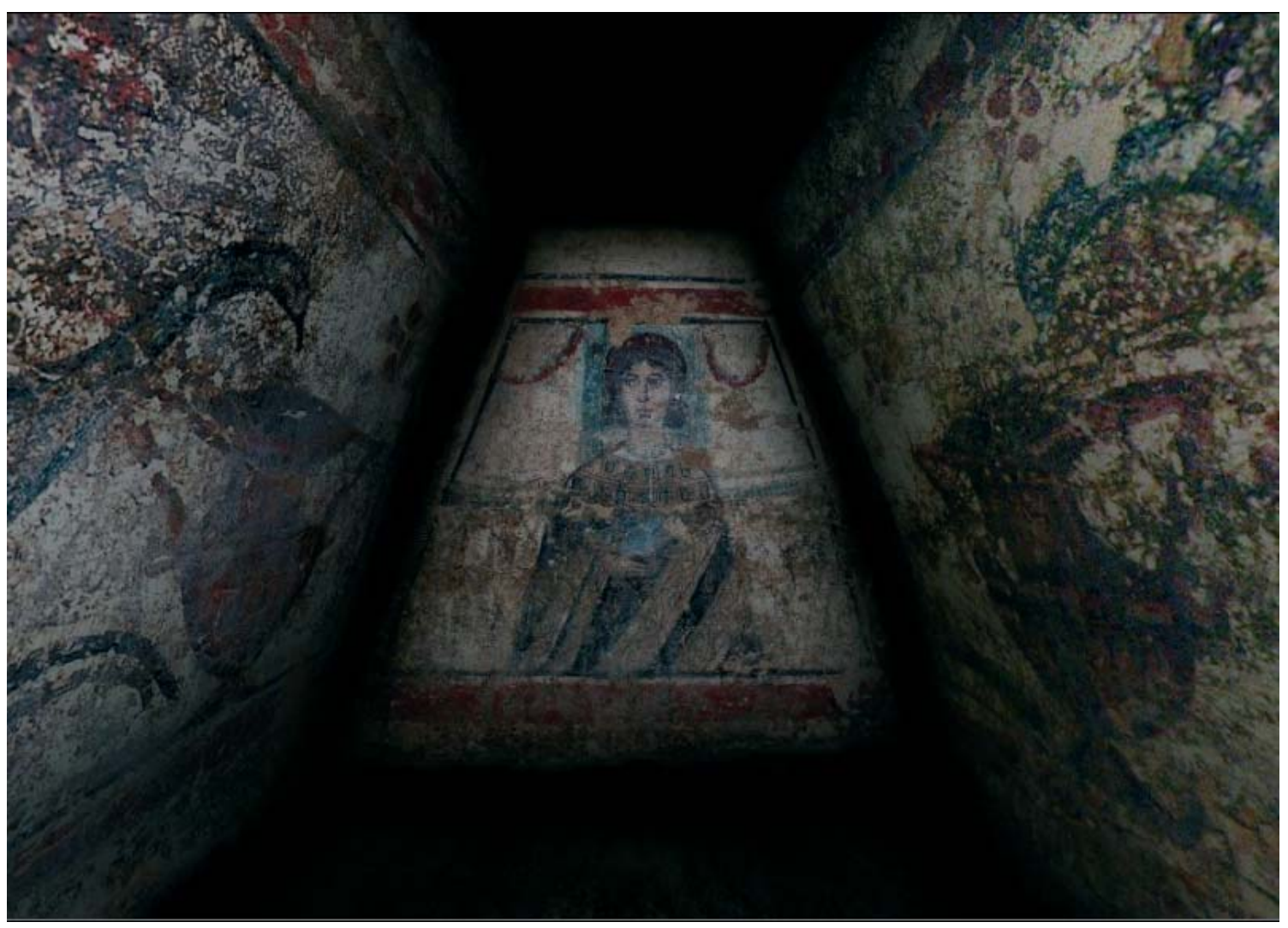

VR tura po Viminacijumu: grobnica sa freskama 
realnost je u virtuelnoj arheologiji zauzela je značajno mesto. Vizuelizacija kulturnog nasleđa je uvek pravila bitnu razliku između istraživačke dokumentacije i materijala namenjenog prezentacijama ili obrazovanju. Upotrebom fotorealističnih virtuelnih panorama ova razlika se veoma smanjila, tako da je kvalitet sadržaja vizuelne informacije minimalno žrtvovan u njegovoj reprezentaciji.

U projektu "Viminacium lumen meum" uspešno je postignut optimalan odnos umetničke interpretacije $\mathrm{i}$ istraživačke prakse, čime je sačuvana autentičnost i relevantnost prezentovanih informacija.

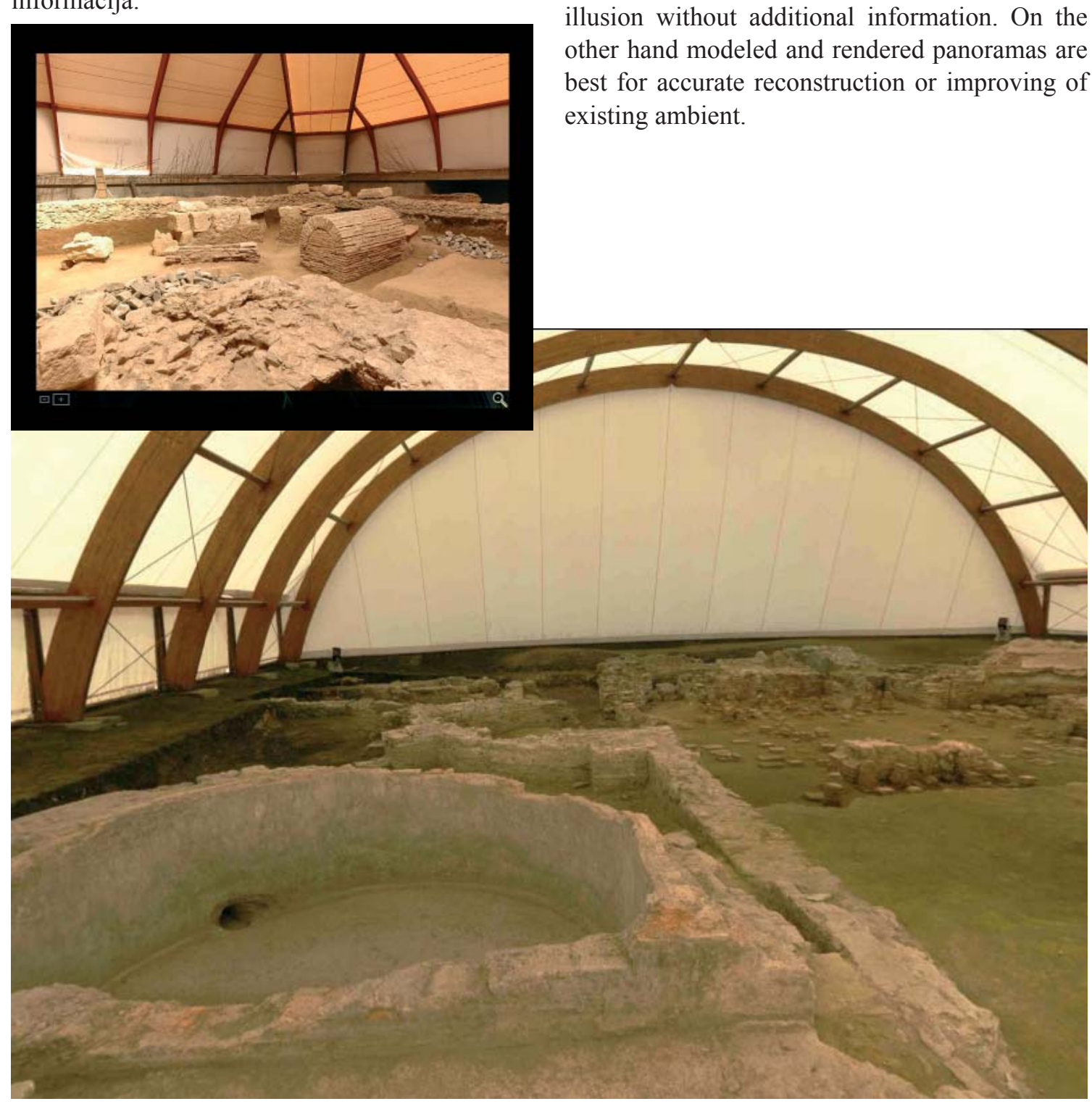

VR tura po Viminacijumu: mauzolej i terme

\section{RESUME \\ Application of VR Panoramas in visuelisation of Cultural Heritage - "Viminacium lumen meum" interactive CD-ROM}

Virtual simulation of space and buildings in visualization of cultural heritage has enormous importance for accuracy and authenticity of spatial information. It enables the effect of being view.

Important characteristic of photographed VR panoramas is the impression of reality and $3 \mathrm{D}$ illusion without additional information. On the other hand modeled and rendered panoramas are best for accurate reconstruction or improving of existing ambient. there and visibility from all angles and points of 


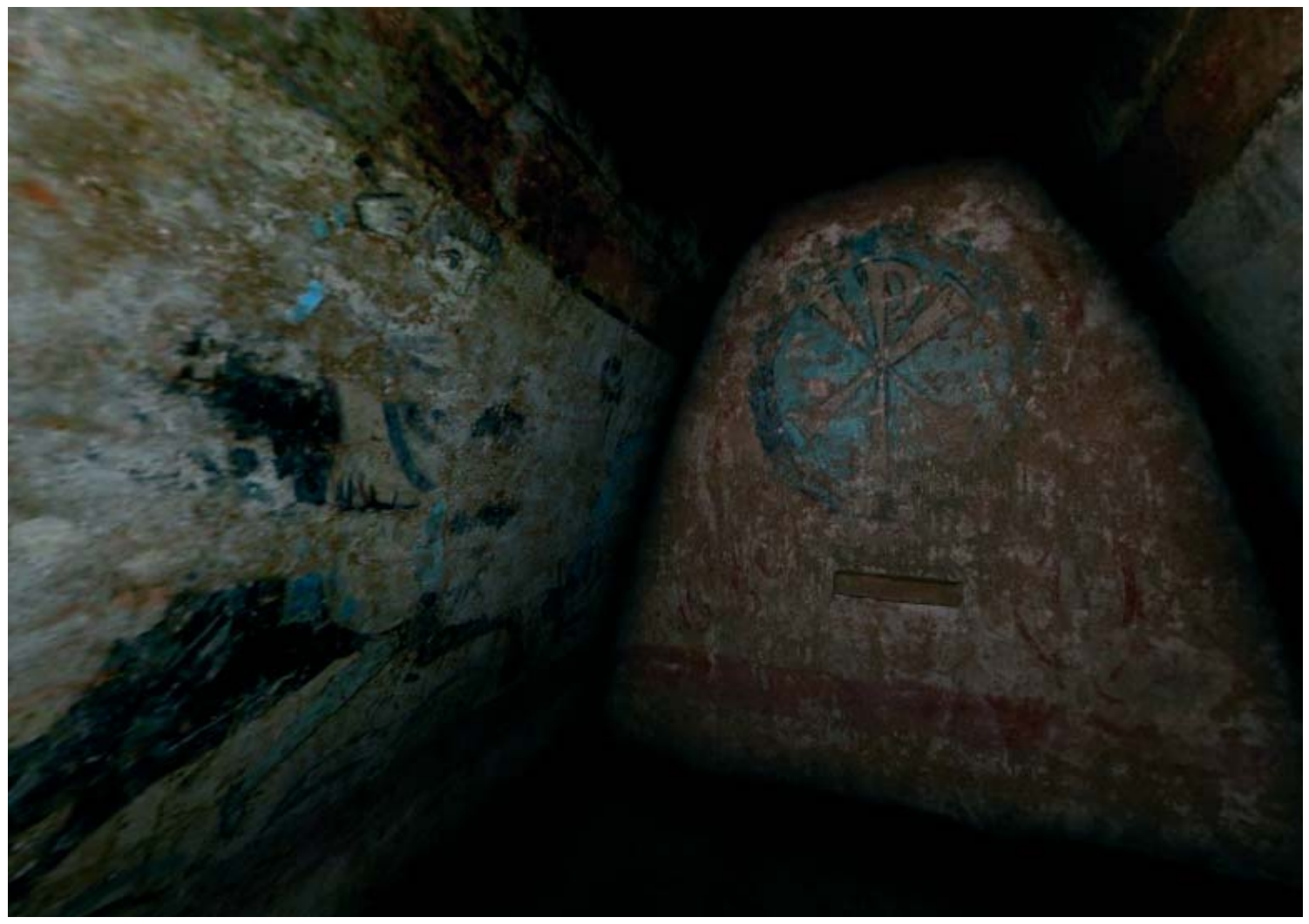

VR tura po Viminacijumu: grobnica sa freskama

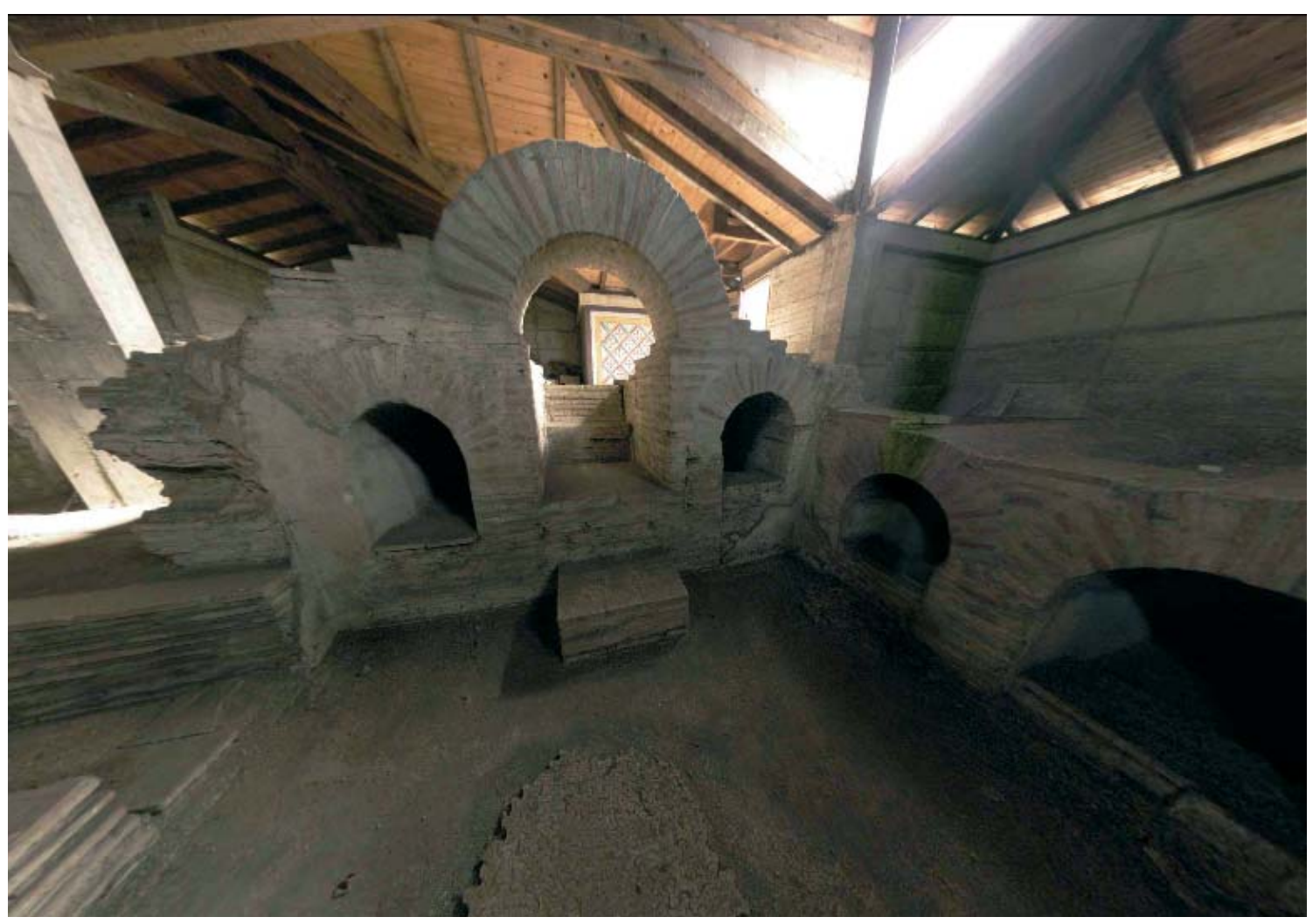

VR tura po Viminacijumu: memorija 